\title{
Dermoscopy of piloleiomyoma
}

\section{Obraz dermoskopowy piloleiomyoma}

\author{
Joanna Pogorzelska-Dyrbuś', Jacek Pająk² \\ '„Estevita” Specialist Medical Practice, Tychy, Polska \\ 2Department of Pathomorphology and Molecular Diagnostics, Medical University of Silesia in Katowice, Poland \\ ' "Estevita” Specjalistyczna Praktyka Lekarska, Tychy, Polska \\ 2Katedra i Zakład Patomorfologii i Diagnostyki Molekularnej, Śląski Uniwersytet Medyczny, Katowice, Polska \\ Dermatol Rev/Przegl Dermatol 2020, 107, 562-565 \\ DOI: https://doi.org// 0.5 I |4/dr.2020. 103893
}

\author{
CORRESPONDING AUTHOR/ \\ ADRES DO KORESPONDENCJI: \\ dr n. med. Joanna Pogorzelska- \\ -Dyrbuś \\ „Estevita” Specjalistyczna \\ Praktyka Lekarska \\ Pasaż Europejski 8/1, 43-100 \\ Tychy, Polska \\ e-mail: jpogorzelskadyrbus@ \\ gmail.com
}

\begin{abstract}
Piloleiomyomas occur rarely and the literature regarding their dermoscopy is scarce. These tumours most commonly present as multiple nodules located on the trunk or the head. The diagnostic difficulties may be caused by their solitary appearance. Therefore, dermoscopy can serve as a non-invasive and accessible diagnostic modality to distinguish leiomyomas from other solitary tumours. This report presents the dermoscopy image of a piloleiomyoma developing on the trunk in a 35-year-old man. A yellowish homogenous background with the presence of delicate network and arborizing telangiectasias on the periphery were present, along with hypopigmented areas. The dermoscopy image of the lesion was characteristic for piloleiomyoma. Unusuall was the abundance of vessels, what is infrequent in this type of tumours.
\end{abstract}

\section{STRESZCZENIE}

Piloleiomyoma to rzadki nowotwór skóry. W literaturze jest niewiele pozycji opisujących obraz dermoskopowy tych nowotworów. Guzki typu piloleiomyoma najczęściej występują $\mathrm{w}$ formie mnogich ognisk umiejscowionych na tułowiu lub na głowie. Ich pojedyncze postaci mogą sprawiać trudności diagnostyczne. Nieinwazyjną i szeroko dostępną metodą diagnostyczną umożliwiającą różnicowanie piloleiomyoma od innych pojedynczych guzów jest dermoskopia. W artykule przedstawiono obraz dermoskopowy guza typu piloleiomyoma rozwijającego się na tułowiu u 35-letniego mężczyzny. W obrazie dermoskopowym zaobserwowano żółtawe, homogenne tło z obecnością delikatnej siatki barwnikowej i teleangiektazji na obrzeżach, a także obszary hipopigmentacji. Chociaż ogólny obraz dermoskopowy zmiany był charakterystyczny dla piloleiomyoma, obfitość naczyń jest rzadkością w tym typie guza.

Key words: dermoscopy, skin tumours, piloleiomyoma.

Słowa kluczowe: dermoskopia, nowotwory skóry, piloleiomyoma. 


\section{INTRODUCTION}

Leiomyomas are rare benign soft tissue neoplasms arising from smooth myocytes. After uterus, skin is their second most common location [1].

Cutaneous leiomyoma is classified in three different variants regarding their origin: vascular - arising from the smooth muscle (tunica media) within the walls of arteries and veins, genital - derived from the dartos muscle of the scrotum and the labia majora as well as those derived from the erectile muscle of the nipple, and most frequent piloleiomyoma arising from arrector pili muscles [2].

Those benign tumours can be solitary, but most frequently present as - often painful - multiple, firm flesh-coloured $0.3-4 \mathrm{~cm}$ nodules located on the trunk or the head, while the solitary lesions are more prevalent on the extremities [3]. The typical age for their onset varies between the second and fourth decade of life [1].

\section{CASE REPORT}

A 35-year-old man with a family history and similar symptoms in his father presented with multiple firm painful brownish nodules located on the trunk (fig. 1). Dermoscopically, there was yellowish homogenous background with the presence of delicate network and linear vessels distributed mainly peripherally (fig. 2). Multiple hypopigmented areas were also present (fig. 3). Diagnosis of leiomyoma was confirmed by histological examination (fig. 4) with immunohistochemistry $($ SMA+, S100-, Desmin +, Calponin +).

\section{DISCUSSION}

Cutaneous leiomyomas are rare lesions, representing approximately $5 \%$ of all leiomyomas, which

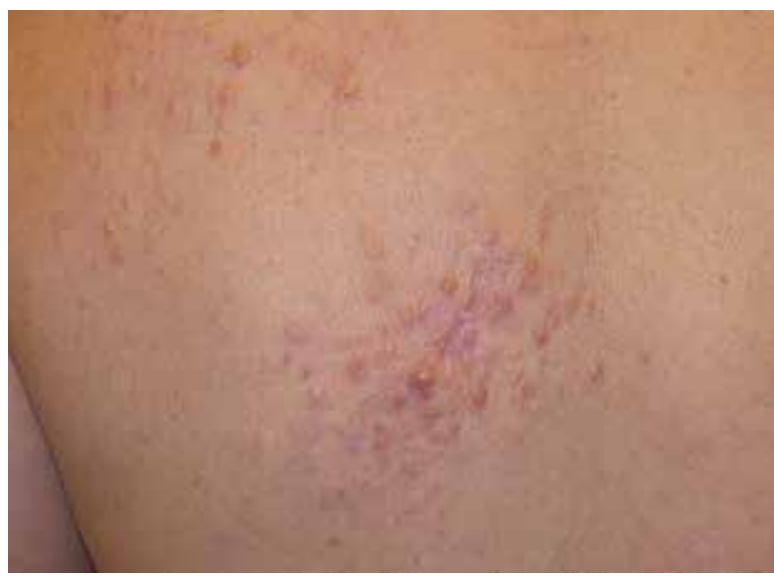

Figure I. Clinical image depicting multiple firm brownish nodules on the patient's trunk

Rycina I. Obraz kliniczny przedstawiający liczne twarde, brązowawe guzki na tułowiu pacjenta

\section{WPROWADZENIE}

Mięśniaki gładkokomórkowe (leiomyoma) są rzadkimi łagodnymi nowotworami tkanek miękkich wywodzącymi się z miocytów mięśni gładkich. Drugą po macicy najczęstszą lokalizacją tego typu guzów jest skóra [1].

W zależności od pochodzenia mięśniaki gładkokomórkowe skóry dzielą się na trzy typy: naczyniowy - guzy powstają w mięśniówce gładkiej (tunica media) w obrębie ścian tętnic i żył; genitalny - guzy wywodzą się z mięśnia błony kurczliwej moszny lub labia majora, lub włókien mięśniowych gładkich odpowiadających za erekcję brodawki sutkowej; piloleiomyoma - najczęściej występujący, wywodzący się z mięśni przywłośnych (arrector pili) [2].

Te łagodne guzy mogą występować pojedynczo, ale najczęściej przybierają postać mnogich, twardych, niejednokrotnie bolesnych guzków barwy cielistej, o wielkości 0,3-4 cm, umiejscowionych na tułowiu lub głowie. Pojedyncze guzy ujawniają się natomiast częściej na skórze kończyn niż w innych lokalizacjach [3]. Zmiany zwykle pojawiają się u pacjentów pomiędzy 3. i 4. dekadą życia [1].

\section{OPIS PRZYPADKU}

Trzydziestopięcioletni mężczyzna zgłosił się do specjalisty z powodu licznych, twardych, bolesnych, brązowawych guzków umiejscowionych na skórze tułowia (ryc. 1). W wywiadzie stwierdzono obciążenie rodzinne (podobne objawy u ojca). W obrazie dermoskopowym zaobserwowano żółtawe, homogenne tło z obecnością delikatnej siatki barwnikowej oraz liniowo przebiegające naczynia krwionośne, zlokalizowanych głównie na obrzeżu (ryc. 2). Stwierdzono również liczne obszary hipopigmentacji (ryc. 3).

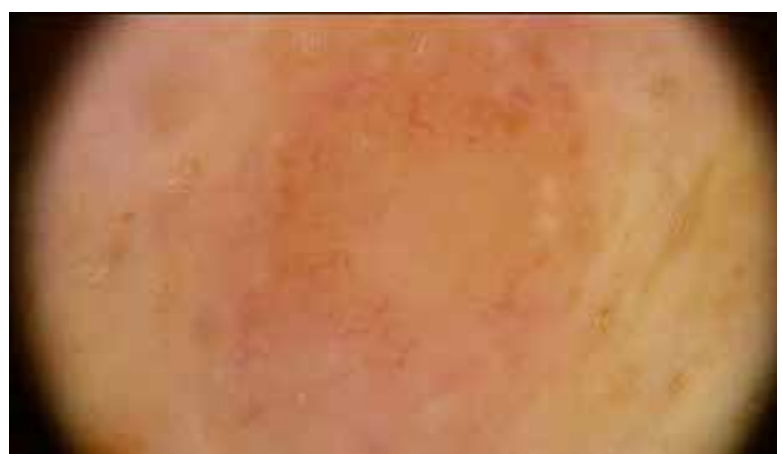

Figure 2. Dermoscopy image of the lesion with linear vessels mainly distributed peripherally

Caption: Image taken by the FotoFinder Medicam 800HD, FotoFinder Systems $\mathrm{GmbH}$, Bad Birnbach, Germany. Magnification: 20X.

Rycina 2. Obraz dermoskopowy zmiany skórnej - widoczne liniowo przebiegające naczynia krwionośne, głównie na obrzeżu Zdjęcie wykonane za pomoca wideodermatoskopu FotoFinder Medicam 800HD, FotoFinder Systems $\mathrm{GmbH}$, Bad Birnbach, Niemcy. Powiększenie: 20X. 


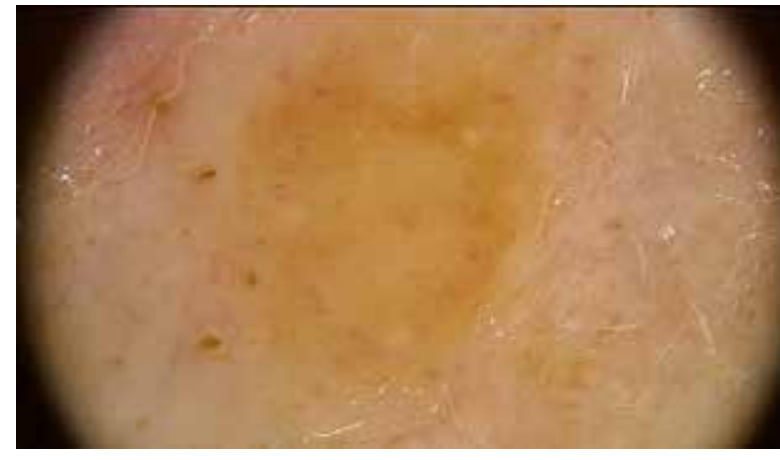

Figure 3. Dermoscopy image of the lesion with multiple hypopigmented areas, linear vessels and a delicate network in the periphery

Caption: Image taken by the FotoFinder Medicam 800HD, FotoFinder Systems GmbH, Bad Birnbach, Germany. Magnification: 20x.

Rycina 3. Obraz dermoskopowy zmiany skórnej - liczne obszary hipopigmentacyjne, liniowo przebiegające naczynia i delikatna siatka barwnikowa na obrzeżu

Zdjęcie wykonane za pomoca wideodermatoskopu FotoFinder Medicam 800HD, FotoFinder Systems GmbH, Bad Birnbach, Niemcy. Powiększenie: 20x.

probably explains why the literature coverage of their clinicopathologic features is limited [4]. However, the use of dermoscopy could be a useful non-invasive diagnostic method, especially in case of the occurrence of a solitary lesion.

The most common dermoscopic pattern of piloleiomyoma is a hypopigmented central area with a symmetric delicate pigment network, however, the dermoscopic features of pilar leiomyomas can be also less specific, as the linear irregular crypts, cerebriform pattern, cloud-like area with branching vessels, fingerprint pattern or even scar-like area can sometimes be observed [5].

In the study of leiomyomas by Zaballos et al., the delicate pigment network was observed in $96.5 \%$ of studied piloleiomyomas, while the vascular structures in the form of unfocused arborizing telangiectasias were present in $15.8 \%$ of these neoplasms [5].

In our study, the vascular structures were present and located at the periphery of the lesion and this finding is a feature more typical for angioleiomyoma [5].

Clinical differential diagnosis of leiomyoma includes other nodules like dermatofibroma, angiolipoma, glomus tumour, eccrine spiradenoma, neurofibroma and dermal nevi and dermatofibrosarcoma protuberans (DFSP). Worth noting is the fact that the dermoscopy image of DFSP, due to its invasiveness, is the most clinically important differential diagnosis of the leiomyoma. The image of DFSP generally consists of central white or pink areas surrounded by structureless light-brown areas with focal pigmented reticular lines, although usually without any vascular pattern [6].

Finally, the screening for renal cancer is mandatory, because hereditary leiomyomatosis and renal cell

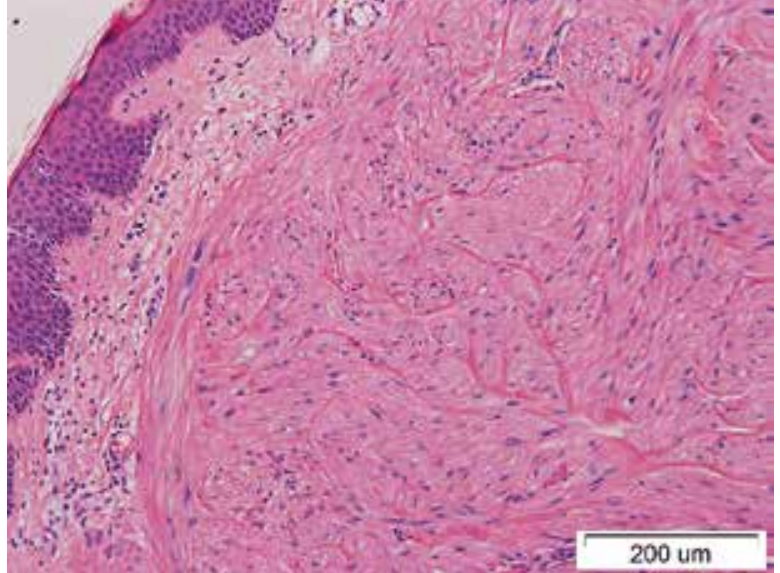

Figure 4. Smooth muscle pattern in the dermis Haematoxylin \& eosin staining. Magnification by $100 \times$.

Rycina 4. Układ mięśni gładkich w skórze właściwej Barwienie hematoksyling i eozynq. Powiększenie 100x.

Rozpoznanie mięśniaka gładkokomórkowego potwierdzono badaniem histologicznym (ryc. 4) oraz immunohistochemicznym (SMA+, S100-, desmina + , kalponina + ).

\section{OMÓWIENIE}

Mięśniaki gładkokomórkowe skóry występują rzadko, stanowią zaledwie ok. 5\% wszystkich mięśniaków gładkokomórkowych. Prawdopodobnie z tego powodu w literaturze można znaleźć jedynie nieliczne prace opisujące cechy kliniczno-patologiczne tych nowotworów [4]. Pomocną nieinwazyjną metodą diagnostyczną - zwłaszcza u pacjentów, u których występują pojedyncze zmiany tego typu - może być dermoskopia.

W obrazie dermoskopowym mięśniaków gładkokomórkowych skóry typu piloleiomyoma najczęściej widoczna jest centralna strefa hipopigmentacji z delikatną, symetryczną siatką barwnikową. Zdarzają się jednak również mniej swoiste cechy dermoskopowe - liniowo rozmieszczone, nieregularne zagłębienia (krypty), struktury przypominające mózg, obszary o wyglądzie chmury z rozgałęzionymi naczyniami, wzór przypominający linie papilarne, a czasem również twory zbliżone wyglądem do blizny [5].

Zaballos i wsp. zaobserwowali delikatną siatkę barwnikową w 96,5\% badanych mięśniaków gładkokomórkowych typu piloleiomyoma. Struktury naczyniowe w postaci rozproszonych, drzewkowatych teleangiektazji występowały natomiast w 15,8\% analizowanych nowotworów tego typu [5].

W opisywanym przypadku struktury naczyniowe były umiejscowione na obrzeżu zmiany, co jest cechą typową dla naczyniakomięśniaków gładkokomórkowych (angioleiomyoma) [5].

W diagnostyce różnicowej mięśniaków gładkokomórkowych należy uwzględnić inne rodzaje zmian 
cancer syndrome (HLRCC) is a genetic disorder that predisposes individuals to multiple cutaneous leiomyomas [1].

\section{CONCLUSIONS}

Dermoscopy as a non-invasive and easily accessible technique can greatly improve the diagnostic accuracy of these neoplasms.

\section{CONFLICT OF INTEREST}

The authors declare no conflict of interest. guzkowych, takie jak włókniakomięsak skóry, naczyniakotłuszczak, kłębczak, gruczolak potowy ekrynowy, nerwiakowłókniak, a także znamiona skórne i włókniakomięsak guzowaty skóry (dermatofibrosarcoma protuberans - DFSP). Szczególną uwagę należy zwrócić na obraz dermoskopowy DFSP. Ze względu na wysoką inwazyjność, z klinicznego punktu widzenia jest to najważniejszy typ nowotworu, który należy uwzględnić w diagnostyce różnicowej mięśniaka gładkokomórkowego. W obrazie dermoskopowym DFSP widoczne są centralne białe lub różowe plamy otoczone bezstrukturalnymi obszarami w kolorze jasnobrązowym, z ogniskowo rozmieszczonymi siateczkowatymi liniami o wzmożonej pigmentacji, zazwyczaj bez wzoru naczyniowego [6].

Niezbędne są również badania przesiewowe w kierunku raka nerki ze względu na zespół HLRCC (hereditary leiomyomatosis and renal cell cancer syndrome - dziedziczne mięśniaki gładkokomórkowe i rak nerkowokomórkowy), który charakteryzuje się dziedziczną predyspozycją do występowania mnogich mięśniaków gładkokomórkowych skóry [1].

\section{WNIOSKI}

Dermoskopia jako nieinwazyjna i szeroko dostępna metoda badania zmian skórnych może znacząco zwiększyć dokładność diagnostyczną w przypadku tego typu nowotworów.

\section{KONFLIKT INTERESÓW}

Autorzy nie zgłaszają konfliktu interesów.

\section{References}

\section{Piśmiennictwo}

1. Patel V.M., Handler M.Z., Schwartz R.A., Lambert W.C.: Hereditary leiomyomatosis and renal cell cancer syndrome: an update and review. J Am Acad Dermatol 2017, 77, 149-158.

2. Malhotra P., Walia H., Singh A., Ramesh V.: Leiomyoma cutis: a clinicopathological series of 37 cases. Indian J Dermatol 2010, 55, 337-341.

3. Paschoal F.M., Rezze G.G.: Dermoscopic findings in a patient with multiple piloleiomyomas. Dermatol Pract Concept 2012, 2, 204-206.

4. Behera B., Vinupriya S., Kumari R., et al.: Dermoscopic features of pilar leiomyomas. Br J Dermatol 2018, 179, 202-204.

5. Zaballos P., Del Pozo L.J., Argenziano G., et al.: Dermoscopy of cutaneous smooth muscle neoplasms: a morphological study of 136 cases. J Eur Acad Dermatol Venereol 2019, 33, 693-699.

6. Venturini M., Zanca A., Manganoni A.M., Pavoni L., Gualdi G., Calzavara-Pinton P.: In vivo characterization of recurrent dermatofibrosarcoma protuberans by dermoscopy and reflectance confocal microscopy. J Am Acad Dermatol 2016, 75, 185-187.

Received: 21.07 .2020

Accepted: 7.09 .2020

Otrzymano: $21.07 .2020 \mathrm{r}$

Zaakceptowano: 7.09.2020 r.

How to cite this article

Pogorzelska-Dyrbuś J., Pająk J.: Dermoscopy of piloleiomyoma. Dermatol Rev/Przegl Dermatol 2020, 107, $562-565$.

DOI: https://doi.org/10.5114/dr.2020.103893 